\section{The National Survey of Local Anaesthesia for Ocular Surgery. I. Survey methodology and current practice}

series have demonstrated a low but significant incidence of life-threatening adverse events, including brain-stem depression and circulatory collapse, with both RBA and PBA. ${ }^{10,15-18}$ Deaths have been reported. ${ }^{19}$ There have been many documented cases of needle trauma to structures within the orbit, some of which result in permanent loss of sight. ${ }^{20-31}$

Any new LA technique should be at least as safe, effective and acceptable as its predecessors. Recently, subconjunctival anaesthesia (SCA), ${ }^{32,33}$ sub-Tenon's (parabulbar) anaesthesia (STA) ${ }^{34-36}$ and purely topical anaesthesia (TA), ${ }^{12,37}$ sometimes with additional intracameral lignocaine, ${ }^{38}$ have become popular. There have been many small studies that have demonstrated good results with these newer techniques. Series of several hundred cases each indicate a reasonable safety record, ${ }^{38-40}$ though no published series is large enough to assess the incidence of rare, lifethreatening adverse events.

To encourage safe administration of LA for intraocular surgery, a working party was set up, comprising representatives of the Royal College of Anaesthetists and the College of Ophthalmologists. Guidelines were published in $1993 .{ }^{41}$ The Guidelines state that all patients undergoing cataract or similar major eye surgery under LA should have a pre-operative assessment, to include a full history and examination, blood pressure measurement and urinalysis. Most patients will also require blood tests and electrocardiography (ECG), as set out in the Guidelines. During the operation the patient should be monitored by pulse oximetry, ECG and blood pressure measurement, in addition to verbal contact. Intravenous access should be obtained, and an anaesthetist should be present in case resuscitation is required.

These recommendations have not been universally accepted, partly due to the shortage of anaesthetists in some hospitals and partly due to the perception that LA is generally safe.
T. Eke

J.R. Thompson

Clinical Audit

Sub-Committee

Royal College of Ophthalmologists

17 Cornwall Terrace Regent's Park London NW1 4QW, UK

This work was presented in part as a free paper at the 1997 Annual Congress of the Royal College of Ophthalmologists

The authors have no proprietary interests relevant to this paper

This project was supported by a grant from the Department of Health to Core Audit Funds at the Royal College of Ophthalmologists

Received: 19 August 1998 Accepted in revised form: 29 January 1999 
It was against this background that the National Survey of Local Anaesthesia for Ocular Surgery was conceived. The main aims of the Survey were:

- to measure the current usage of the various types of anaesthesia for ocular surgery,

- to establish whether LA is administered in a safe manner,

- to estimate the incidence and severity of adverse events associated with LA,

- to provide the basis of a review of the published Guidelines.

Planning of the Survey involved collaboration between members of the Quality of Practice Committee of the Royal College of Anaesthetists, and the Clinical Audit Sub-Committee of the Royal College of Ophthalmologists.

\section{Method}

This prospective, observational study was designed to include all National Health Service (NHS) operating theatres performing intraocular surgery in the United Kingdom. The main period of data collection was 1 September to 30 November 1996.

Ethical aspects of the Survey design were discussed with representatives of the Department of Health and a Local Ethics Committee. It was agreed that, because the Survey is purely observational, there was no requirement to seek ethics approval from individual local committees before commencing the Survey.

Initial contact questionnaires were sent to all consultant ophthalmologists, and heads of department of anaesthesia in hospitals with an ophthalmology department. These served to introduce the Survey, and to assess attitudes and previous experience of LA. A letter to theatre nurses requested addresses of all theatres where NHS intraocular surgery was performed by surgeons from their unit, including theatres in other hospitals. Packs of Survey forms were then posted to each theatre. In order that the Survey should have as little effect on clinical practice as possible, the actual dates were only announced 1-2 weeks before data collection commenced.

Ideally, the Survey would have looked at many variables, over a long period of time. However, to request full details of every LA given over weeks or months would be unacceptable, and result in poor participation. As a compromise, participants were asked to complete a Report Form for every LA administered during the first week of the Survey, then to report adverse events only for the remainder of the 3-month period. The Report Form comprised a single sheet of A4 paper, and asked relatively simple questions that could be answered by any member of theatre staff. It included questions about the patient's age and gender, the intended operation, LA technique, anaesthetist involvement and any adverse events. More complex questions, including details of patient's general health, medications and pre-operative investigation, appeared on the Adverse Event Form, and hence these data were only available for those patients in whom an adverse event occurred. Eligibility criteria were simple: all NHS cases in which LA was administered for the purpose of intraocular surgery, during the Survey period. An 'Adverse Event' was defined as 'something which made you monitor the patient more closely, or take action'. To encourage participation, each operating theatre was provided with a poster to remind staff of the Survey, and all the forms, instructions and reply paid envelopes were presented together in a free-standing plastic dispenser.

To encourage full and frank reporting, the Report Forms had no identifying codes or other marks. It was therefore impossible for us to tell from which hospital a Report Form had been sent, thus guaranteeing the anonymity of all respondents. However, we did wish for follow-up information on certain patients: to this end we included an optional section for clinicians to enter their name and address at the end of the Adverse Event Form.

Follow-up questionnaires were sent to consenting clinicians who had reported adverse events, and all responses were double-entered onto a database for subsequent analysis.

A validation protocol was designed, to allow calculation of the participation rate, and the total number of GAs and LAs given. Validation involved inspecting the theatre records of a representative sample. The 178 eye units on a Royal College of Ophthalmologists database were classified into three categories: major academic units, other units recognised for basic specialist training in ophthalmology, and units without recognition. From these three categories, a total of 22 units were selected at random, and 21 of these allowed us to inspect their Eye Theatre records for the first week of the study. By comparing totals from the theatre records of these 'Validation Units' and from returned forms, we were able to estimate the total number of LA intraocular operations performed in the UK for that week. The ratio of GA to LA was calculated from the theatre records of the Validation Units. In making these calculations, we made appropriate corrections for the different surgical workload in the three categories of eye unit. To further verify our response rates, the blank Report Forms sent to the Validation Units were of a slightly darker colour than those distributed elsewhere.

To calculate the number of LAs given in the 3-month period, a correction was made for workload. Department of Health figures show that national surgical workload varies from week to week, and is significantly affected by such factors as school holidays and the national holiday at the end of August. The Department of Health can provide weekly totals for intraocular operations performed in England and Wales, but does not record the type of anaesthetic used. As 1996 figures are not expected until late 1998, data from the financial year 1991-2 were used instead. The year 1991 was chosen because 1 September fell on a Sunday, the same day as in 1996. In 1991-2, 1:586\% of eye operations were performed in the first week of September, and $26.58 \%$ in the period 1 September to 30 November. This factor (i.e. $16.76 \times$ first week) was used to correct for workload. 
Table 1. Preferred method of anaesthesia for cataract surgery: consultant ophthalmologists and heads of department of anaesthesia

\begin{tabular}{llc}
\hline & \multicolumn{2}{c}{$\begin{array}{c}\text { Preferred } \\
\text { anaesthetic type }\end{array}$} \\
\cline { 2 - 3 } & $\mathrm{GA}$ & $\mathrm{LA}$ \\
\hline $\begin{array}{l}\text { Consultant ophthalmologists (all) } \\
\begin{array}{l}\text { Older ophthalmologists } \\
\quad \text { (in post }>19 \text { years) }\end{array}\end{array}$ & $29 \%$ & $71 \%$ \\
$\begin{array}{l}\text { Younger ophthalmologists } \\
\quad \text { (in post <11 years) }\end{array}$ & $41 \%$ & $59 \%$ \\
Heads of department of anaesthesia & $13 \%$ & $76 \%$ \\
\hline
\end{tabular}

Standard errors and confidence intervals were calculated on a log scale using the delta method so as to combine the uncertainty in the validation study, the first week and the reported events over 3 months. In this way, estimates were made for the total number of intraocular operations performed in the whole United Kingdom.

\section{Results}

Response rates were good at all stages of the Survey. The initial contact questionnaires were anonymous and unmarked, hence individual reminders could not be sent: 510 of 685 ophthalmologists (74.5\%) and 138 of 178 heads of anaesthesia $(77.5 \%)$ returned completed questionnaires. With the exception of a few ophthalmologists who never performed intraocular surgery, no respondent refused to participate in the main part of the Survey.

The initial questionnaire showed that most consultant ophthalmologists preferred LA over GA when performing cataract surgery, and that this trend is stronger among younger consultants (Table 1). Ophthalmologists were asked about the availability of anaesthetists to cover their LA intraocular surgery in NHS hospitals. Of the 510 respondents, 250 (49\%) stated that an anaesthetist was always available to cover their LA lists, and overall $72 \%$ of cases were said to be covered. Forty-nine ophthalmologists $(9.6 \%)$ stated that they never had an anaesthetist in theatres when performing intraocular surgery under LA. Sixty-four $(12.5 \%)$ stated that they sometimes operated under LA when there was no anaesthetist in the hospital, and 31 (6\%) stated that they sometimes operated when there was neither an anaesthetist nor a cardiac arrest team available on site. The 510 respondents had a total of 4915 years' experience as consultant ophthalmologist. There were ten reports of patient death, attributed to LA complications, in this period. The questionnaire did not ask about other serious complications, but several respondents described cases in which patients might have died were it not for the intervention of an anaesthetist.

For the main part of the Survey, packs of forms were sent to a total of 306 operating theatres, as identified by theatre nurses. Surgeons from the 178 units operated in a total of 200 NHS hospitals. There were 43 theatres for the 21 Validation Units and their associated hospitals. Inspection of theatre record books from the Validation Units showed that workload per theatre was higher in the 'academic' units, and lowest in the 'non-recognised' units. A proportionate correction was made for this when calculating participation and LA usage rates.

In the first week, 2827 correctly completed local anaesthetic Report Forms were returned. A further 128 forms were excluded, either because the date had not been entered or because the procedure did not fulfil the entry criteria.

Using the data from the Validation Units as described above, we calculated that participation in the first week was $72.8 \%$ (95\% confidence interval (CI): 56.4-93.9\%). We estimate that the actual number of eligible LAs given in the country in that week was 3884 (95\% CI: 2895-4873). Using the workload correction factor described above, this extrapolates to 65100 LAs in the whole 3-month period (95\% CI: 48 500-81 700). The number of LAs administered for intraocular surgery annually in the NHS is therefore calculated to be 245000 (95\% CI: 182 500-307 000). The relative frequency of use of the different LA techniques were calculated from the firstweek returns, and are presented in Table 2.

The proportion of intraocular surgery performed using GA and LA was calculated from the theatre records of the Validation Units, making appropriate corrections for workload. It was found that $24.2 \%$ of intraocular surgery was performed using GA, 70\% using LA alone and 5.8\% using LA with sedation.

Anaesthesia for cataract surgery was assessed separately, and is summarised in Tables $3 a$ and $3 b$. Calculations were made using theatre records from the first week of the Survey. Validation Unit data, pooling LA and GA cases, indicated that $66 \%$ of cataract surgery was performed using phacoemulsification and $34 \%$ by

Table 2. Use of the various LA techniques for intraocular surgery in 1996

\begin{tabular}{|c|c|c|c|c|}
\hline LA technique & $\begin{array}{l}\text { No. of reports } \\
\quad \text { (week 1) }\end{array}$ & Relative frequency & $\begin{array}{l}\text { Estimated no. of LAs given in } 3 \text { months } \\
(95 \% \text { confidence intervals })\end{array}$ & $\begin{array}{l}\text { Proportion of patients } \\
\text { given facial block }\end{array}$ \\
\hline Peribulbar & 1854 & $65.6 \%$ & $42700(33000-55100)$ & $2 \%$ \\
\hline Retrobulbar & 479 & $16.9 \%$ & $11000(8400-14400)$ & $13 \%$ \\
\hline Sub-Tenon's & 190 & $6.7 \%$ & $4380(3280-5840)$ & $3 \%$ \\
\hline Subconjunctival & 124 & $4.4 \%$ & $2860(2100-3880)$ & $2 \%$ \\
\hline Topical alone & 81 & $2.9 \%$ & $1870(1340-2600)$ & $1 \%$ \\
\hline Intracameral & 2 & $0.07 \%$ & $46(11-188)$ & 0 \\
\hline Combinations & 63 & $2.3 \%$ & $1450(1020-2060)$ & 0 \\
\hline Not stated & 34 & $1.2 \%$ & $780(510-1190)$ & $3 \%$ \\
\hline Total & 2827 & & $65100(48500-81700)$ & \\
\hline
\end{tabular}


Table 3a. Phacoemulsification: use of the various anaesthetic techniques (data summarised from returns for the first week of the Survey)

\begin{tabular}{lcccc}
\hline Anaesthetic used & $\begin{array}{c}\text { No. of reports in } \\
\text { first week }\end{array}$ & Relative frequency & $\begin{array}{c}\text { Proportion given oral } \\
\text { premedication and/or sedated }\end{array}$ & $\begin{array}{c}\text { Proportion managed } \\
\text { as day-case }\end{array}$ \\
\hline General anaesthetic (GA) & - & $13 \%$ & - & - \\
Peribulbar & 963 & $65 \%$ of LA & $9 \%$ & $74 \%$ \\
Retrobulbar & 229 & $15 \%$ of LA & $5 \%$ & $77 \%$ \\
Sub-Tenon's & 105 & $7 \%$ of LA & $3 \%$ & $56 \%$ \\
Subconjunctival & 92 & $6 \%$ of LA & $3 \%$ & $98 \%$ \\
Topical alone & 64 & $4 \%$ of LA & 0 & $87 \%$ \\
Intracameral & 2 & $0.1 \%$ of LA & - & - \\
Combinations/LA not stated & 37 & - & & $100 \%$ \\
\hline
\end{tabular}

'conventional' extracapsular or endocapsular surgery. Calculations for LA alone were made using returns from all units in the first week of the Survey: $1492(59 \%)$ phacoemulsification, 1015 (40\%) 'conventional' extracapsular, one intracapsular and 27 unspecified cataract procedures were reported. Validation Unit data were used to calculate the proportion of cataract surgery performed using general anaesthesia in Tables $3 a$ and $3 b$.

The degree of involvement of anaesthetists is summarised in Table 4, which is also derived from the first-week returns. This table records the proportion of LAs given by anaesthetists and ophthalmologists, for each of the LA techniques. The availability of an anaesthetist to manage any problems is also recorded.

Table 4 also summarises the extent to which the 1993 safety Guidelines ${ }^{41}$ were being followed. Data on monitoring, intravenous access and availability of an anaesthetist were sought for all patients in the first week of the Survey. Data on pre-operative assessment were felt to be too cumbersome to collect on all cases, so were only requested on the Adverse Event Forms. During the initial week, an anaesthetist was available (in the theatre or in an adjacent theatre) for $84 \%$ of cases of intraocular surgery performed under LA. In $3 \%$ of cases there was neither anaesthetist nor cardiac arrest team in the hospital at the time of surgery. Intravenous access was obtained in $60 \%$ of cases, though in $5 \%$ this was not done until after the LA had been given. Monitoring took place in $96 \%$ of patients ( $93 \%$ had pulse oximetry, $41 \%$ blood pressure monitoring, 55\% ECG), though only $35 \%$ had all three modalities, and $4 \%$ had no peroperative monitoring at all. Two per cent of retrobulbar, $2 \%$ of peribulbar, $5 \%$ of sub-Tenon's, $35 \%$ of subconjunctival and $24 \%$ of topical anaesthetics had no monitoring. Only $27 \%$ of cases had the full complement of intravenous access, anaesthetist available and three modalities of monitoring, as recommended in the Guidelines.

The design of the Survey meant that details of preoperative assessment were available only for those patients who had adverse events. Full data on preoperative assessment were available for 182 patients, 169 of whom had either peribulbar or retrobulbar LA. All these patients had a general health assessment: in 162 cases this was done by a doctor, and in 20 cases by a nurse. Medical history was recorded in the case-notes of 168 patients $(92 \%)$, and blood pressure (BP) in $156(87 \%)$. Findings of examination with a stethoscope were recorded in 64 patients. Urinalysis was recorded in 59 patients $(32 \%)$, and $49 \%$ of patients had a record neither of urinalysis nor of any blood test in their case-notes. In $31 \%$ of patients the medical history, BP and urinalysis were all recorded. In $7 \%$ of cases the Guidelines were complied with in full (medical history, BP, urinalysis, intravenous access, monitoring of all three modalities and an anaesthetist available). Because of the small number of forms received, it was not possible to make a formal comparison of the degree of pre-operative assessment for different LA techniques. However, no major differences were apparent.

The reasons for incomplete availability of anaesthetists were explored in the questionnaire sent to heads of departments of anaesthesia. Sixty-six per cent of respondents (92/138) thought that all of their unit's LA intraocular surgery was covered by an anaesthetist, who would be either in theatre or in an adjacent theatre. Overall, responding anaesthetists estimated that $84 \%$ of their LA surgery was covered. Consultant ophthalmologists had estimated this same figure to be $72 \%$; the actual figure from the Survey was $84 \%$. Seven respondents, all in District General Hospitals, stated that

Table 3b. 'Conventional' extracapsular cataract extraction (extracapsular or endocapsular): use of the various anaesthetic techniques (data summarised from returns for the first week of the Survey)

\begin{tabular}{lcccc}
\hline Anaesthetic used & $\begin{array}{c}\text { No. of reports in } \\
\text { first week }\end{array}$ & $\begin{array}{c}\text { Proportion given oral } \\
\text { Relative frequency }\end{array}$ & $\begin{array}{c}\text { Proportion managed } \\
\text { premedication and or sedated }\end{array}$ \\
\hline General anaesthetic (GA) & - & $33 \%$ & - & $7 \%$ \\
Peribulbar & 700 & $69 \%$ of LA & $9 \%$ & $9 \%$ \\
Retrobulbar & 199 & $20 \%$ of LA & $44 \%$ \\
Sub-Tenon's & 67 & $7 \%$ of LA & $100 \%$ & $38 \%$ \\
Subconjunctival & 10 & $1 \%$ of LA & - & $10 \%$ \\
Topical alone & 3 & $0.3 \%$ of LA & - \\
Intracameral & 0 & 0 of LA & - \\
Combinations/LA not stated & 36 & - & - \\
\hline
\end{tabular}


Table 4. Involvement of an anaesthetist for the various LA techniques (data summarised from the first week of the Survey)

\begin{tabular}{|c|c|c|c|c|c|c|c|c|c|c|}
\hline \multicolumn{3}{|l|}{ LA technique } & \multicolumn{2}{|c|}{ LA given by } & \multicolumn{4}{|c|}{ Availability of anaesthetist } & \multicolumn{2}{|c|}{ Safety measures } \\
\hline LA used & $\begin{array}{l}\text { Proportion } \\
\text { given } \\
\text { oral pre- } \\
\text { medication }\end{array}$ & $\begin{array}{l}\text { Proportion } \\
\text { given } \\
\text { IV } \\
\text { sedation }\end{array}$ & $\begin{array}{c}\text { Anaesthe- } \\
\text { tist }\end{array}$ & $\begin{array}{l}\text { Ophthal- } \\
\text { mologist }\end{array}$ & $\begin{array}{l}\text { Dedicated } \\
\text { anaesthe- } \\
\text { tist for } \\
\text { the list }\end{array}$ & $\begin{array}{c}\text { In } \\
\text { theatres, } \\
\text { but } \\
\text { attending } \\
\text { another } \\
\text { list }\end{array}$ & $\begin{array}{l}\text { Available } \\
\text { in } \\
\text { dire } \\
\text { emergency } \\
\text { only }\end{array}$ & $\begin{array}{c}\text { No } \\
\text { anaesthe- } \\
\text { tist in } \\
\text { hospital }\end{array}$ & $\begin{array}{c}\text { IV } \\
\text { access }\end{array}$ & $\begin{array}{l}\text { Monitor- } \\
\text { ing }\end{array}$ \\
\hline Peribulbar & $3 \%$ & $6 \%$ & $54 \%$ & $45 \%$ & $68 \%$ & $22 \%$ & $8 \%$ & $2 \%$ & $65 \%$ & $97 \%$ \\
\hline Retrobulbar & $4 \%$ & $4 \%$ & $31 \%$ & $69 \%$ & $48 \%$ & $31 \%$ & $17 \%$ & $3 \%$ & $64 \%$ & $97 \%$ \\
\hline Sub-Tenon's & $2 \%$ & $3 \%$ & $14 \%$ & $86 \%$ & $36 \%$ & $36 \%$ & $27 \%$ & $1 \%$ & $63 \%$ & $95 \%$ \\
\hline Subconjunctival & $10 \%$ & 0 & $12 \%$ & $86 \%$ & $36 \%$ & $16 \%$ & $32 \%$ & $16 \%$ & $20 \%$ & $65 \%$ \\
\hline Topical alone & 0 & $3 \%$ & $7 \%$ & $33 \%$ & $43 \%$ & $6 \%$ & $44 \%$ & $6 \%$ & $24 \%$ & $76 \%$ \\
\hline Intracameral & 0 & 0 & 0 & $100 \%$ & $100 \%$ & - & - & - & $100 \%$ & $100 \%$ \\
\hline
\end{tabular}

IV, intravenous.

none of their LA intraocular surgery was covered by an anaesthetist. Reasons for incomplete cover were given as: $56 \%(26 / 46)$ staffing problems, $4 \%$ (2) policy of anaesthetists, $13 \%$ (6) policy of ophthalmologists, $15 \%$ (7) combined policy, $2 \%$ (1) policy of hospital managers.

\section{Discussion}

The Survey has demonstrated that local anaesthesia (LA) is now the most commonly used technique of anaesthesia for ocular surgery in the United Kingdom. Overall, 70\% of intraocular surgery was performed using LA alone, $5.8 \%$ under LA with sedation and $24.2 \%$ using GA. We calculate that approximately a quarter of a million LAs were given for intraocular surgery in 1996, of which twothirds were peribulbar anaesthesia, one-sixth retrobulbar anaesthesia and the other one-sixth made up of subTenon's, subconjunctival, topical and intracameral anaesthesia (see Table 2). While actual figures are not available for the UK as a whole, our calculated figure is in broad agreement with Department of Health figures for ophthalmic surgical activity in England and Wales. The prevalence of LA, and use of the newer LA techniques, is broadly in line with practice in other countries. ${ }^{4,6,7}$

Cataract remains the most common indication for intraocular surgery, ${ }^{42}$ and phacoemulsification is now the most common surgical approach. In 1990, the National Cataract Surgery Survey showed that less than $4 \%$ of cataract surgery was by phacoemulsification and $46 \%$ of cataract surgery was done using LA. ${ }^{1}$ This 1996 survey indicates that the figures were $66 \%$

phacoemulsification and $80 \%$ LA. However, it should be remembered that the Survey was not designed to look specifically at cataract surgery: more precise figures are expected from the National Cataract Audit II, which took place in 1997-8.

Recent questionnaire surveys have documented the decline in GA for cataract surgery in the UK. In 1984, 63\% of responding consultant ophthalmologists used GA exclusively for cataract surgery, ${ }^{43}$ though by 1991 only $37 \%$ stated that they used GA 'frequently' (more than $75 \%$ of cases) and $45 \%$ preferred their LA patients to be sedated. ${ }^{2}$ In 1996, our initial contact questionnaire to consultant ophthalmologists suggested that $27 \%$ of cataract surgery was performed using GA, $65 \%$ with LA alone, and $8 \%$ with LA and sedation. These figures agreed closely with actual practice as reported in the Survey. This shift towards LA is due to a variety of factors: LA has been shown to be highly acceptable to patients and hospital staff, and is the favoured technique for day-case surgery. Improvements in surgical technique, particularly the development of small-incision surgery, afford a more controlled operating environment and therefore allow the use of minimal anaesthesia. LA is preferred over GA for cataract surgery by most ophthalmic surgeons and anaesthetists (Table 1). Because LA is even more popular among the younger consultant ophthalmologists, we predict that the use of LA will become even more widespread in the years to come.

The Survey showed that the safety Guidelines, published jointly by the Royal College of Anaesthetists and the Royal College of Ophthalmologists, ${ }^{41}$ are not being followed in a significant proportion of cases. While most patients $(96 \%)$ are monitored, only $35 \%$ had all three of the recommended modalities. An anaesthetist was available in theatres in $84 \%$ of cases and $60 \%$ had intravenous access. Only $27 \%$ of cases fully met all these criteria for theatre safety. Pre-operative evaluation, while more difficult to assess objectively, showed a similar pattern, with all patients having some sort of assessment but only $7 \%$ fully meeting the Guidelines for assessment and theatre safety. Despite this, it was apparent that in many cases the procedure was still carried out to a good safety standard. For example, many of the patients who did not have urinalysis did have ECG and/or blood tests done, and many of those who did not have intravenous access did have an anaesthetist in the theatre.

Conversely, we are aware that some units never perform any routine pre-operative tests, and $6 \%$ of consultant ophthalmologists stated that they sometimes perform intraocular surgery under LA when there is neither an anaesthetist nor a cardiac arrest team in the hospital.

The reasons for not adhering strictly to the Guidelines were not addressed by the Survey, though we are aware that cost, time efficiency, staff availability and patient acceptability are frequently cited. It has been suggested that the Guidelines may be over-cautious in view of the 
low risk of life-threatening problems. In order to review the appropriateness of the Guidelines it is necessary to know the incidence of serious side-effects of the various LA techniques. Safety of retrobulbar and peribulbar anaesthesia has been assessed in a few large series, performed by clinicians with a special interest in the subject. ${ }^{10,15,16}$ However, there has previously been no large study of LA safety in routine practice. The National Survey of Local Anaesthesia for Ocular Surgery has attempted to measure the incidence of such serious adverse events on a national scale, and the results are presented in our companion paper. ${ }^{44}$

\section{References}

1. Courtney (Desai) P. The National Cataract Surgery Survey. I. Method and descriptive features. Eye 1992;6:487-92.

2. Hodgkins PR, Luff AJ, Morrell AJ, Teye Botchway L, Featherston TJ, Fielder AR. Current practice of cataract extraction and anaesthesia. Br J Ophthalmol 1992;76:323-6.

3. Leaming DV. Practice styles and preferences of ASCRS members: 1993 survey. J Cataract Refract Surg 1994;20:459-67.

4. Leaming DV. Practice styles and preferences of ASCRS members: 1997 survey. J Cataract Refract Surg 1998;24:552-61.

5. Sindhu K, Colrain I, Buttery R, Wise G. Survey of local anaesthesia use in cataract surgery in Australia. Aust $\mathrm{N} \mathrm{Z} \mathrm{J}$ Ophthalmol 1991;19:43-8.

6. Oshika T, Masuda K, Hayashi F, Majima Y, Leaming DV. Current trends in cataract and refractive surgery in Japan: 1994 survey. Jpn J Ophthalmol 1995;39:265-73.

7. Norregaard JC, Schein OD, Bellan L, Black C, Alonso J, Bernth-Petersen $P$, et al. International variation in anesthesia care during cataract surgery: results from the international cataract surgery outcomes study. Arch Ophthalmol 1997;115:1304-8.

8. Cooper JM. Development of day-case cataract surgery: a literature review. Br J Nurs 1996;5:1327-33.

9. Forrest FC. Local anaesthesia or general anaesthesia? In: Johnson RW, Forrest FC. Local and general anaesthesia for ophthalmic surgery. Oxford: Butterworth-Heinemann, 1994.

10. Hamilton RC, Gimbel HV, Strunin L. Regional anaesthesia for 12000 cataract extraction and intraocular lens implantation procedures. Can J Anaesth 1988;35:615-23.

11. Campbell DNC, Lim M, Kerr Muir M, O'Sullivan G, Falcon $\mathrm{M}$, Fison $\mathrm{P}$, et al. A prospective randomised study of local versus general anaesthesia for cataract surgery. Anaesthesia 1993;48:422-8.

12. Knapp H. On cocaine and its use in ophthalmic and general surgery. Arch Ophthalmol 1884;13:402-48.

13. Atkinson WS. Retrobulbar injection of anesthetic within the muscular cone. Arch Ophthalmol 1936;16:494-503.

14. Davis DB 2nd, Mandel MR. Posterior peribulbar anesthesia: an alternative to retrobulbar anesthesia. J Cataract Refract Surg 1986;12:182-4.

15. Nicoll JMV, Acharya PA, Ahlen K, Baguneid S, Edge KR. Central nervous system complications after 6000 retrobulbar blocks. Anesth Analg 1987;66:1298-302.

16. Davis DB 2nd, Mandel MR. Efficacy and complication rate of 16224 consecutive peribulbar blocks: a prospective multicenter study. J Cataract Refract Surg 1994;20:327-337. Erratum published in: J Cataract Refract Surg 1994;20:673.

17. Meyers EF, Ramirez RC, Boniuk I. Grand mal seizures after retrobulbar block. Arch Ophthalmol 1978;96:847.

18. Wittpenn JR, Rapoza P, Sternberg P Jr, Kuwashima L, Saklad J, Patz A. Respiratory arrest following retrobulbar anesthesia. Ophthalmology 1986;93:867-70.
19. Haider SA. Survey of the complications associated with current practice of cataract surgery under local anaesthesia. Br J Ophthalmol 1994;78:510-1.

20. Duker JS, Belmont JB, Benson WE, Brooks HL, Brown GC, Federman JL, et al. Inadvertent globe perforation during retrobulbar and peribulbar anesthesia. Ophthalmology 1991;98:519-26.

21. Hay A, Flynn HW Jr, Hoffman JI, Rivera AH. Needle penetration of the globe during retrobulbar and peribulbar injections. Ophthalmology 1991;98:1017-24.

22. Gillow JT, Aggarwal RK, Kirkby GR. A survey of ocular perforation during ophthalmic local anaesthesia in the United Kingdom. Eye 1996;10:537-8.

23. Paulter SE, Grizzard WS, Thompson LN, Wing GL. Blindness from retrobulbar injection into the optic nerve. Ophthalmic Surg 1986;17:334-7.

24. Hersch M, Baer G, Dieckert JP, Lambert HM, Shore JW. Optic nerve enlargement and central retinal artery occlusion secondary to retrobulbar anesthesia. Ann Ophthalmol 1989;21:195-7.

25. Kraushar MF, Seelenfreund MH, Freilich DB. Central retinal artery closure during orbital hemorrhage from retrobulbar injection. Trans Am Acad Ophthalmol Otolaryngol 1974;78:OP65-70.

26. Morgan CM, Schatz H, Vine AK, Cantrill HL, Davidorf FH, Gitter KA, et al. Ocular complications associated with retrobulbar injections. Ophthalmology 1988;95:660-5.

27. Puustjarvi T, Purhonen S. Permanent blindness following retrobulbar hemorrhage after peribulbar anesthesia for cataract surgery. Ophthalmic Surg 1992;23:450-2.

28. Hamed LM. Strabismus presenting after cataract surgery. Ophthalmology 1991;98:247-52.

29. Hamilton SM, Elsas FJ, Dawson TL. A cluster of patients with inferior rectus restriction following local anesthesia for cataract surgery. J Pediatr Ophthalmol Strabismus 1993;30:288-91.

30. Rao VA, Kawatra VK. Ocular myotoxic effects of local anaesthetics. Can J Ophthalmol 1988;23:171-3.

31. Klein ML, Jampol LM, Condon PI, Rice TA, Sergeant GR. Central retinal artery occlusion without retrobulbar hemorrhage after retrobulbar anesthesia. Am J Ophthalmol 1982;93:573-7.

32. Smith R. Cataract extraction without retrobulbar anaesthetic injection. Br J Ophthalmol 1990;74:205-7.

33. Petersen WC, Yanoff M. Subconjunctival anesthesia: an alternative to retrobulbar and peribulbar techniques. Ophthalmic Surg 1991;22:199-201.

34. Greenbaum S. Parabulbar anesthesia. Am J Ophthalmol 1992;114:776.

35. Stevens JD. A new local anaesthesia technique for cataract extraction by one quadrant sub-Tenon's infiltration. Br J Ophthalmol 1992;76:670-4.

36. Fukasaku H, Marron JA. Pinpoint anesthesia: a new approach to local ocular anesthesia. J Cataract Refract Surg 1994;20:468.

37. Grabow HB. Topical anaesthesia for cataract surgery. Eur J Implant Refract Surg 1993;5:20-3.

38. Koch PS. Anterior chamber irrigation with unpreserved lidocaine $1 \%$ for anesthesia during cataract surgery. J Cataract Refract Surg 1997;23:551-4.

39. Fukasaku H, Marron JA. Sub-Tenon's pinpoint anesthesia. J Cataract Refract Surg 1994;20:673.

40. Kershner RM. Clear corneal cataract surgery and the correction of myopia, hyperopia and astigmatism. Ophthalmology 1997;104:381-9.

41. Report of the Joint Working Party on Anaesthesia in Ophthalmic Surgery. London: Royal College of Anaesthetists, College of Ophthalmologists, 1993.

42. Dixon R. Management of cataract. Effective Health Care 1996;2(3). 
43. Wong D, Steele AD. A survey of intraocular lens implantation in the United Kingdom. Trans Ophthalmol Soc UK 1985;104:760-5.
44. Eke T, Thompson JR. The National Survey of Local Anaesthesia for Ocular Surgery. II. Safety profiles of local anaesthesia techniques. Eye 1999;13:196-204. 